\title{
Commentary: The time has come to establish guidelines for reporting outcomes after coronary artery bypass grafting surgery
}

\author{
Harold L. Lazar, MD
}

\author{
From the Division of Cardiac Surgery, Boston University School of Medicine, Boston, Mass. \\ Disclosures: Author has nothing to disclose with regard to commercial support. \\ Received for publication Jan 7, 2019; accepted for publication Jan 8, 2019; available ahead of print Feb 13, 2019. \\ Address for reprints: Harold L. Lazar, MD, 80 E Concord St, Boston, MA 02118 (E-mail: harold.1.lazar@ gmail. \\ com). \\ J Thorac Cardiovasc Surg 2019;158:1356-8 \\ $0022-5223 / \$ 36.00$ \\ Copyright (C) 2019 Published by Elsevier Inc. on behalf of The American Association for Thoracic Surgery \\ https://doi.org/10.1016/j.jtcvs.2019.01.027
}

Female sex has traditionally been a risk factor for increased short- and long-term morbidity and mortality after coronary artery bypass grafting (CABG) surgery. ${ }^{1}$ Female patients were found to be less likely to receive cardioprotective medications, such as angiotensin-converting-enzyme inhibitors, statins, and antiplatelet medication, and to be more likely to present with acute coronary syndromes, impaired left ventricular function, and increased comorbidities, such as active smoking, chronic obstructive pulmonary disease, hypertension, hypercholesterolemia, and poorly controlled diabetes mellitus. They also had smaller caliber coronary arteries with more diffuse disease, which is associated with decreased long-term graft patency. The increased awareness of the prevalence of coronary artery disease in women has resulted in an increased use of statins and antibetes. Furthermore, the implementation of tight glycemic control has significantly decreased perioperative morbidity and mortality in female patients with diabetes undergoing CABG, especially the incidence of deep sternal wound infections (DSWIs). ${ }^{2,3}$

In this edition of the Journal, Vrancic and colleagues ${ }^{4}$ found that female sex is no longer a risk factor for longterm mortality after $\mathrm{CABG}$ in patients receiving bilateral internal thoracic artery (BITA) grafts. ${ }^{4}$ This study evaluated 4406 patients undergoing CABG from 2000 to 2017. BITA grafting was performed in $67.6 \%$ of patients, of whom 10.1\% (299 patients) were female. Propensity matching (PM) was used to account for differences in preoperative risk factors. In the unmatched analysis of all patients undergoing BITA grafting, female patients were older and had higher incidences of peripheral vascular disease, anemia, and nonelective surgery. In the unmatched analysis, relative to male patients undergoing BITA grafting, female patients undergoing BITA grafting had a higher perioperative mortality $(2.3 \%$ vs $1.0 \% ; P=.024)$ and a higher incidence of DSWI $(3.3 \%$ vs $1.5 \% ; P=.022)$. In platelet agents and a tighter control of hypertension and dia-

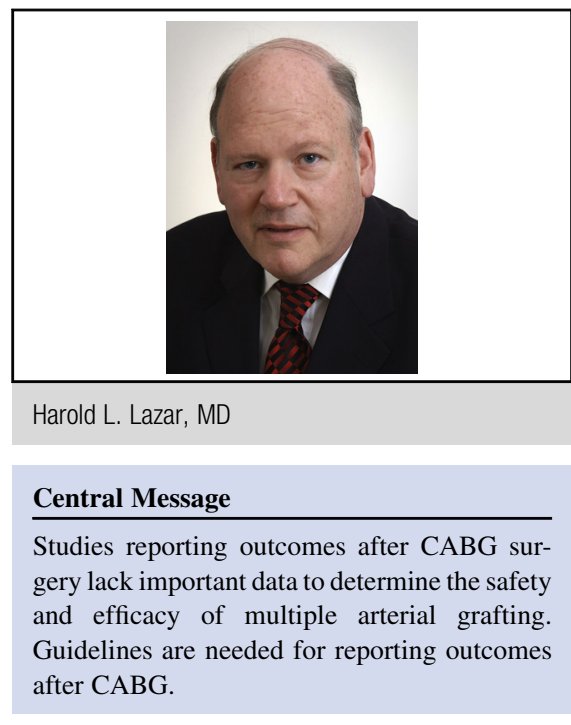

See Article page 1345 . the PM analysis, there were no significant differences in mortality or DSWI between male and female patients who underwent BITA grafting. In the PM analysis, BITA grafting in female patients resulted in equivalent long-term survival to that of male patients. All female patients undergoing BITA grafting had increased long-term survival compared with female patients with single internal thoracic artery (SITA) grafts $(86.4 \%$ vs $76.1 \% ; P=.041)$. In the subpopulation of female patients younger than 65 years, there was no significant difference in long-term survival between patients receiving BITA vs SITA grafts. In the PM analysis, however, among female patients older than 65 years (considered "elderly" in this study), BITA grafting resulted in superior long-term survival compared with SITA $(87 \%$ vs $73 \% ; P=.019)$. In the unmatched analysis, female patients BITA were more likely to be smokers, have a family history of coronary artery disease, have had a previous myocardial infarction, and have higher incidences of peripheral vascular disease, chronic obstructive pulmonary disease, renal dysfunction, and left main disease. In the unmatched analysis, patients undergoing SITA who were older than 65 years had a higher perioperative mortality $(5.7 \%$ vs $3.2 \% ; P=.016)$ but a lower incidence of DSWI $(0.7 \%$ vs $3.8 \% ; P=.068)$. In the PM analysis, female patients 
undergoing BITA also had a lower incidence of perioperative mortality ( $3.1 \%$ vs $5.5 \% ; P=.73)$ but a higher incidence of DSWI ( $3.8 \%$ vs $0.8 \% ; P=.99)$.

In view of these results, should BITA grafting be performed in all female patients undergoing CABG? Unfortunately, there are several issues with this study that limit the conclusions that can be made. Vrancic and colleagues ${ }^{4}$ selected age greater than 65 years as indicative of "elderly" patients. The definition of "elderly," however, must take into account both biological and social issues. Chronologic age alone cannot accurately describe an elderly patient without considering functional status, such as frailty, cognitive function, and other comorbidities. Because the mean age of female patients in both PM and non-PM analyses in this study was 67 years, a cutoff of greater than 75 years would have been more appropriate to encompass "elderly" patients. Furthermore, after PM adjustments, there were only 131 female patients older than 65 years in either the BITA or SITA groups, thus limiting the statistical power for further analyses of this population. In the unmatched analysis, patients undergoing SITA in this study had more risk factors. Society of Thoracic Surgeons predicted risk of mortality scores should have used as one of the matching parameters. Clearly, there was a selection bias in determining which patients received a BITA graft, especially among female patients older than 65 years.

A major observation of this study is that BITA grafting in female patients older than 65 years resulted in a significant survival advantage relative to female patients receiving a SITA graft. No information, however, is provided as to what the mechanism for this enhanced survival was. No data were provided regarding graft patency, the need for repeat revascularization procedures, or the incidence of hospital readmissions for recurrent angina or myocardial infarction. Vrancic and colleagues ${ }^{4}$ note that the need for additional revascularization was not an objective of this study and "will be the reason for a future paper." This is an important piece of data, however, and it should be part of any CABG study reporting long-term outcomes. Furthermore, no information is provided regarding the causes of death in these patients. In the methods section, we are told that mortality was due to cardiac causes in $21.3 \%$ of patients but unknown in $35.5 \%$. These data should have been reported for all the patient groups, especially those patients older than 65 years. In a recent study examining causes of death after CABG, cardiovascular deaths were most frequent during the first year after $\mathrm{CABG}$, reflecting the perioperative morbidity of the surgery. ${ }^{5}$ Patients who survived the first postoperative year were more likely to die of causes other than cardiovascular disease. If BITA grafting is responsible for the enhanced survival in "elderly" patients, data should be provided to show that patients undergoing BITA grafting have a higher incidence of graft patency, have lower incidences of myocardial infarction and the need for a repeat revascularization procedure, have greater freedoms from angina and congestive heart failure, and are less likely to die of cardiac causes.

Although BITA grafting has been shown to increase long-term survival in some CABG populations, it is associated with a higher risk of DSWI, especially in obese female patients who have poorly controlled insulindependent diabetes, who are smokers, and who have chronic obstructive pulmonary disease. In the study of Vrancic and colleagues, ${ }^{4}$ even after PM, the risk of DSWI was greater than $3 \%$ in female patients undergoing BITA grafting. Unfortunately, Vrancic and colleagues ${ }^{4}$ have not told us the prevalence of patients with insulindependent diabetes or their preoperative hemoglobin $A_{1 c}$ levels. This information is important in determining which patients undergoing BITA are at higher risk for DSWI-a complication that increases both short- and long-term mortality. Kieser and coworkers ${ }^{6}$ found that obese female patients with diabetes accounted for only $13 \%$ of their CABG patients but accounted for $38 \%$ of all DSWIs. ${ }^{6}$ When they eliminated this group from BITA grafting, their incidence of DSWI fell from $3.1 \%$ to $0 \%$. The influence of BITA grafting on long-term survival in patients with diabetes may also be determined by the need for insulin therapy. Schwann and colleagues ${ }^{7}$ found that improved longterm survival with multiarterial grafting in patients with diabetes was largely driven by the enhanced survival of patients with non-insulin dependent disease, with only minimal impact among those with insulin-dependent disease. Enhanced long term-survival in female patients undergoing CABG may be explained not only by BITA grafting but by also by the increased use of guideline-directed cardioprotective medications, including $\beta$-blockers, statins, antiplatelet agents, and angiotensin-converting-enzyme inhibitors.

Unfortunately, the deficits in data on preoperative risk factors, intraoperative grafting strategies, and long-term outcomes are all too common among current CABG studies. The absence of these data and the lack of uniform definitions for the severity of comorbidities and appropriate short- and long-term end points limit conclusions regarding the safety and efficacy of BITA and multiarterial grafting and, most importantly, our ability to determine which groups of patients will benefit most from BITA and multiarterial grafting and for whom these techniques should be avoided. We currently have society guidelines that set the standards for reporting and defining appropriate clinical endpoints for studies involving open aortic valve replacement, transcatheter aortic valve replacement, and surgical ablation procedures. $^{8-10}$ Is it not time to develop guidelines for reporting outcomes after CABG surgery as well? 


\section{References}

1. Roques F, Nashef SA, Michel P, Gauducheau E, de Vincentis C, Baudet E, et al. Risk factors and outcome in European cardiac surgery: analysis of the EuroSCORE multinational database of 19030 patients. Eur J Cardiothoracic Surg. 1999; 15:816-22.

2. Lazar HL, Chipkin SR, Fitzgerald CA, Bao Y, Cabral H, Apstein CS. Tight glycemic control in diabetic coronary artery bypass graft patients improves periop erative outcomes and decreases recurrent ischemic events. Circulation. 2004; 209:1497-502.

3. Lazar HL, McDonnell M, Chipkin SR, Furnary AP, Engelman RM, Sadhu A, et al; Society of Thoracic Surgeons Blood Glucose Guideline Task Force. The Society of Thoracic Surgeons practice guideline series: blood glucose management during adult cardiac surgery. Ann Thorac Surg. 2009;87:663-9.

4. Vrancic JM, Navia DO, Espinoza JC, Piccinini F, Camporrtondo M Benzadon $\mathrm{M}$, et al. Is sex a risk factor for death in patients with bilateral internal thoracic artery grafts? J Thorac Cardiovasc Surg. 2019;158:1345-53.e1.

5. Butt JH, Sørensen R, Bäck C, Olsen PS, Thorsteinsson K, Torp-Pederson C, et al Short- and long-term cause of death in patients undergoing isolated coronary artery bypass grafting: a nationwide cohort study. J Thorac Cardiovasc Surg. 2018;156:54-60.e4.

6. Kieser TM, Rose MS, Aluthman V, Montgomery M, Louie T, Belenke I. Toward zero: deep sternal wound infections after 1001 consecutive coronary artery bypass grafting using arterial grafts: implications for diabetic patients. J Thorac Cardiovasc Surg. 2014;148:1887-95.

7. Schwann TA, Al-Shaar L, Engoren M, Habib RH. Late effects of radial artery vs saphenous vein grafts for multi-vessel coronary bypass surgery in diabetics: a propensity matched analysis. Eur J Cardiothoracic Surg. 2013;44:701-10.

8. Guidelines for reporting morbidity and mortality after cardiac valvular operations. Ann Thorac Surg. 1988;46:257-9.

9. Kappetein AP, Head SJ, Généreux P, Piazza N, van Mieghen NM, Blackstone EH, et al. Updated standardized endpoint definitions for transcatheter aortic valve implantation: the Valve Academic Research Consortium-2 consensus document. J Am Coll Cardiol. 2012;60:1438-54.

10. Shemin RJ, Cox JL, Gillinov AM, Blackstone EH, Bridges CR. Guidelines for reporting data and outcomes for the surgical treatment of atrial fibrillation. Ann Thorac Surg. 2007;83:1225-30. 